removing in the first place the need for such extensive immunosuppressive therapy by attempting to achieve the best possible tissue match before operation.

We are grateful to Professor D. N. S. Kerr, Professor J. Swinney, and Mr. R. Taylor for permission to examine patients under their care.

\section{References}

Armstrong, D., Balakrishnan, S. L., Steger, L., Yu, B., and Stenzel, K. H. (1971). Arquives of Internal Medicine, 127, 111.

Ashton, N., and Cunha Vaz, J. G. (1966). Arquivos Portugueses de Oftalmologia, 18, Suppl., p. 39.

Black, R. L., Oglesby, $\dot{R}^{39}$, Von Sallman, L., and Bunim, J. (1960). fournal of the American Medical Association, 174, 166.

Bossen, E. H., Johnston, W.W., Amatulli, J., and Rowlands, D.T. (1969). American fournal of Clinical Pathology, 52, 340.

Burde, R. M., and Becker, B. (1970). Fournal of the American Medical Association, 213, 2075.

Craighead, J. E., Hanshaw, J. B., and Carpenter, C. B. (1967). Journal of the American Medical Association, 201, 725.

de Venecia, G., ZuRhein, M., Pratt, M. V., and Kisken, W. (1971). Archives of Ophthalmology, $86,44$.

Diosi, P., Moldovan, E., and Tomescu, N. (1969). British Medical fournal, 4, 660 .
Embil, J. A., Haldane, E. V., MacKenzie, R. A. E., and Van Rooyen, C. E. (1969). Canadian Medical Association fournal, 101, 730.

Giles, C. L., Mason, G. C., Duff, I. F., and MacLean, J. A. (1962). Fournal of the American Medical Association, 182, 719.

Goldman, H. (1962). Archives of Ophthalmology, 68, 621.

Harris, J. L. (1960). American fournal of Ophthalmology, 49, 351.

Hedley-White, E. T., and Craighead, J. E. (1965). New England fournal of Medicine, 272, 473

Kääriäinen, L., Klemola, E., and Paloheimo, J. (1966). British Medical fournal, 1, 1270.

Kanich, R. E., and Craighead, J. E. (1966). American fournal of Medicine, 40, 874.

Kern, R. Zaruba, K., and Scheitlin, W. (1970). Ophthalmic Research, 1, 21. Lang, D. J., and Hanshaw, J. B. (1969). New England fournal of Medicine, $280,1145$.

Lang, D. J., Scolnick, E. M., and Willerson, J. T. (1968). New England Fournal of Medicine, 278, 1147.

Miller, S. J. H. (1956). Transactions of the Ophthalmological Society of the United Kingdom, 85, 289.

Paloheimo, J. A., Van Essen, R., Klemola, E., Kääriäinen, L., and Siltanen, P. (1968). American fournal of Cardiology, 22, 624

Rifkind, D. (1966). Fournal of Laboratory and Clinical Medicine, 68, 463.

Rifkind, D., Goodman, N., and Hill, R. B. (1967). Annals of Internal Medicine, 66, 1116

Smith, M. E. (1964). Archives of Ophthalmology, 72, 44

Stern, H., and Elek, S. D. (1965). Fournal of Hygiene, 63, 79

Stevens, D. P., Barker, L. F. Ketchman, A. S., and Meyer, H. M. (1970) Fournal of the American Medical Association, 211, 1341 .

Wallow, I. (1969). Berichte der Deutschen Ophthalmologischen Gesellschaft $70,55$.

Williamson, J., et al. (1969). British fournal of Ophthalmology, 53, 361.

Wong, T. W., and Warner, N. E. (1962). Archives of Pathology, 74, 403.

\title{
Liquor Bilirubin Levels and False Prediction of Severity in Rhesus Haemolytic Disease
}

\author{
B. R. PRIDMORE, E. G. ROBERTSON, W. WALKER
}

British Medical fournal, 1972, 3, 136-139

\section{Summary}

Liquor bilirubin levels gave a false prediction of outcome for the fetus in 80 out of 716 rhesus-sensitized women referred for treatment during 1965-9. Trauma caused by amniocentesis seemed to be responsible for an increase in the severity of immunization in a significant proportion of cases. In addition, contamination of liquor samples by plasma, particularly fetal plasma, completely invalidated liquor bilirubin estimations. Errors in estimation of gestational length were also found to be associated with misleading results and a poor fetal prognosis.

\section{Introduction}

Variations in the level of bilirubin in liquor amnii are closely related to the severity of rhesus haemolytic disease in the fetus and are used to identify those patients in whom special treatment is needed to prevent intrauterine death. Liquor is obtained by amniocentesis, but as this is potentially dangerous we prefer initially to select patients for this investigation on the basis of the previous obstetric history (Walker, 1968).

First Affected Pregnancy.-Initial amniocentesis is performed at 31 weeks, but only if the maternal antibody titre by the indirect Coombs technique against Group $\mathrm{OR}_{1} \mathrm{R}_{2}$ cells is $1: 16$ or greater.

Department of Obstetrics and Gynaecology, University of Newcastle upon Tyne

B. R. PRIDMORE, M.B., M.R.C.o.G., Registrar

E. G. ROBERTSON, M.D., M.R.c.o.G., Senior Lecturer

Department of Child Health, University of Newcastle upon Tyne W. WALKER, M.D., Reader
Previous Liveborn Affected Infant.-Initial amniocentesis is performed at 31 weeks. No account is taken of the maternal antibody titre.

Previous Stillbirth due to Rhesus Disease (Including Liveborn Hydrops Fetalis).-Amniocentesis is first performed at between 20 and 24 weeks of pregnancy. No account is taken of maternal antibody titre.

Incorrect predictions occur; high levels of bilirubin are sometimes found in liquor when the infant is not severely affected, and, conversely, low levels can be associated with severe rhesus haemolytic disease or even stillbirth. "Over" prediction can lead to unnecessary intrauterine transfusion or premature induction, both of which are dangerous, while "under" prediction means that a fetus may die unnecessarily.

In the present study we examined cases in which an incorrect forecast of severity was made in order to determine whether a satisfactory explanation of failure is possible.

\section{Subjects and Method}

During 1965-9 810 rhesus-negative women with antibodies were booked for delivery in the Princess Mary Maternity Hospital and 716 of them had one or more specimens of liquor examined. For this investigation the patients were admitted to hospital overnight and amniocentesis was performed under strict aseptic precautions. The liquor, once obtained, was placed in a brown bottle to exclude light and the bilirubin level estimated within a few hours by the method described by Knox et al. (1965).

With a $0.5-\mathrm{cm}$ light path the spectrum is constructed through the visible range $360-630 \mathrm{~nm}$. The optical density difference between 520 and $490 \mathrm{~nm}$ wavelengths is measured and as this is a logarithmic function it may also be expressed as a transmittance ratio:

$\%$ transmission at $520 \mathrm{~nm}$ 
Both the optical density difference and this ratio give a direct measure of the quantity of bilirubin present. The level is then used to make a decision about the timing of further amniocentesis or to plan active treatment.

In practice we regard three levels of bilirubin as critically important. Ratios above or below 1.06 give the best discrimination between stillbirth and livebirth, but stillbirths occasionally occur with ratios as low as $1 \cdot 04$. Values above $1 \cdot 1$, particularly if rising, indicate a serious risk of imminent intrauterine death. In practice, if the bilirubin level was low (ratio less than 1.04) between 31 and 35 weeks we would leave the pregnancy to go to spontaneous delivery, and would not repeat amniocentesis. If the ratio was greater than 1.04 we would repeat amniocentesis in two weeks. Two consecutive ratios above 1.1 and rising are taken as an indication for intrauterine transfusion, while ratios rising to between 1.06 and 1.1 would be regarded as an indication for premature induction, provided that the pregnancy was known with certainty to be of at least 35 weeks' gestation.

It is not realistic to expect precise prediction in all cases and we therefore consider it satisfactory to include very severe liveborn haemolytic disease (cord haemoglobin value less than $7.5 \mathrm{~g} / 100 \mathrm{ml}$ ) in the same category as stillbirth. In fact many such infants were hydropic at birth, unlikely to survive and almost certainly would have benefited from earlier active treatment.

For the purpose of the present study we have defined wrong predictions by the following rigid criteria on the grounds that such objective categorization was necessary to evaluate the cause of error:

Underprediction.-Liquor ratio less than 1.06 but at delivery the infant was either stillborn or if liveborn the cord haemoglobin was less than $7.5 \mathrm{~g} / 100 \mathrm{ml}$.

Overprediction.-The liquor ratio was greater than 1.06 but the infant was liveborn with a cord haemoglobin value greater than $7.5 \mathrm{~g} / 100 \mathrm{ml}$

Patients treated by intrauterine transfusion have been excluded from this study.

\section{Results}

Wrong predictions as defined were made in 80 cases-overpredictions in 56, underpredictions in 24 .

\section{UNDERPREDICTION}

Of the 24 cases, 10 resulted in stillbirth, while 14 were liveborn but very severely affected, and three of these died in the neonatal period. One stillbirth was associated with a severe abruptio placentae 10 days after the last amniocentesis, and as the infant showed no evidence of haemolytic disease at necropsy it is excluded from further consideration. The results in the remaining cases are summarized in Table I. All three infants who died in the neonatal period had severe haemolytic disease, but

TABLE I-Relation between Amniocentesis and Survival of Fetus in Underpredicted Cases

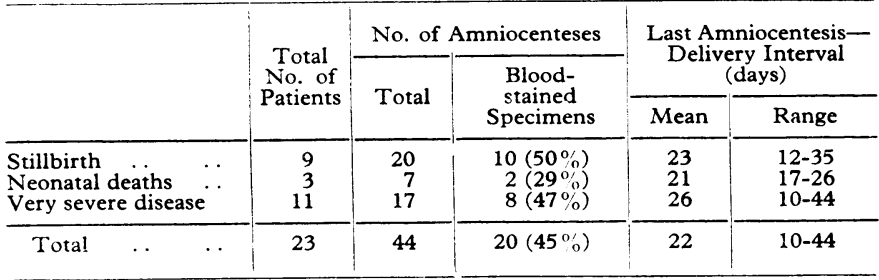

the actual cause of death in one was intracranial haemorrhage, in another severe hyaline membrane disease, and in the third ruptured spleen. The overall perinatal mortality was $52 \cdot 1 \%$.
In the underpredicted cases there was a $45 \%$ incidence of blood-stained taps. Robertson et al. (1967) showed this to occur in only $22 \%$ of cases if the placental site is located before amniocentesis, compared with $50 \%$ if the placental site is not known. Previous placental location had been ascertained in 17 of the 23 cases under consideration and allowing for this the corrected figure for blood-stained taps should be $29 \%$. This difference is not quite statistically significant $\left(\chi^{2}=4 \cdot 46 ; 2\right.$ D.F. $)$ but the suggestion is that trauma may be related to underprediction. In fact three mothers had rigors after withdrawal of blood-stained liquor and there was additional haematological evidence that large feto-maternal bleeds had occurred. All three fetuses died within $\mathbf{4 8}$ hours of amniocentesis.

It is also plausible that small feto-maternal haemorrhages occurring in association with amniocentesis could boost sensitization of the mother, and this effect would be more pronounced where there was a long interval between amniocentesis and delivery. Such an effect of transplacental haemorrhage should be reflected in a rise of maternal antibody titre. In Table II

TABLE II-Change in Antibody Titre between Last Amniocentesis and Delivery

\begin{tabular}{|c|c|c|c|c|c|c|}
\hline \multirow{2}{*}{$\begin{array}{c}\text { Change in } \\
\text { Antibody } \\
\text { Titre }\end{array}$} & \multicolumn{3}{|c|}{ Underpredictions } & \multicolumn{3}{|c|}{ Overpredictions } \\
\hline & $\begin{array}{l}\text { Clear } \\
\text { Liquor }\end{array}$ & $\begin{array}{l}\text { Blood- } \\
\text { stained } \\
\text { Liquor }\end{array}$ & Total & $\begin{array}{c}\text { Clear } \\
\text { Liquor }\end{array}$ & $\begin{array}{l}\text { Blood- } \\
\text { stained } \\
\text { Liquor }\end{array}$ & Total \\
\hline $\begin{array}{l}\text { No rise } \\
1-2 \text { tubes } \\
3-4 \text { tubes } \\
5+\text { tubes }\end{array}$ & $\begin{array}{l}1 \\
4 \\
0 \\
1\end{array}$ & $\begin{array}{l}0 \\
5 \\
6 \\
2\end{array}$ & $\begin{array}{l}1 \\
9 \\
6 \\
3\end{array}$ & $\begin{array}{r}18 \\
7 \\
8 \\
3\end{array}$ & $\begin{array}{l}6 \\
5 \\
5 \\
1\end{array}$ & $\begin{array}{r}24 \\
12 \\
13 \\
4\end{array}$ \\
\hline Total & 6 & 13 & 19 & 36 & 17 & 53 \\
\hline
\end{tabular}

changes in antibody titre between the time of the first amniocentesis and the time of delivery are summarized both for the cases in which underprediction occurred and also for those in which severity was overestimated.

The relevant data were available only for 19 of the 23 underpredictions and for 53 of the 56 overpredictions. This is mainly because delivery titres were not routinely carried out on patients in whom stillbirth occurred, which unfortunately are the most germane to this study.

In the underpredicted cases 18 out of 19 showed a rise in antibody titre whereas this occurred in oniy 29 out of 53 cases in the overpredicted group. In both groups rises in titre were associated with "bloody taps," and changes in antibody titre in relation to blood contamination of the liquor for all cases are shown in Table III. The difference between the two groups is

TABLE III-Relation between Blood-staining of Liquor at Amniccentesis and Change in Antibody Titre between Last Amniocentesis and Delivery (All Cases)

\begin{tabular}{|c|c|c|c|c|c|}
\hline \multicolumn{4}{|c|}{$\begin{array}{c}\text { Change in } \\
\text { Antibody Titre }\end{array}$} & \multirow{2}{*}{$\begin{array}{c}\begin{array}{c}\text { Clear } \\
\text { Liquor }\end{array} \\
19(45 \cdot 2 \%) \\
11(26 \cdot 2 \%) \\
12(28 \cdot 6 \%)\end{array}$} & \multirow{2}{*}{$\begin{array}{c}\begin{array}{c}\text { Blood-stained } \\
\text { Liquor }\end{array} \\
6(20 \cdot 0 \%) \\
10(33.3 \%) \\
14(46.7 \%)\end{array}$} \\
\hline $\begin{array}{l}\text { No rise } \\
1-2 \text { tubes } \\
3+\text { tubes }\end{array}$ & $\begin{array}{l}\ldots \\
\cdots \\
\cdots\end{array}$ & $\begin{array}{l}\cdots \\
\cdots\end{array}$ & $\begin{array}{l}\ldots \\
\cdots \\
\cdots\end{array}$ & & \\
\hline Total & $\ldots$ & . & $\ldots$ & $42(100 \%)$ & $30(100 \%)$ \\
\hline
\end{tabular}

statistically highly significant $(P<0.001)$ and even if only large titre rises of three or more dilutions are considered this difference is still present $(P=0.025)$. However, although there is a relation between trauma and increased maternal antibody titre, it is more difficult to associate this with an increase in the severity of haemolytic disease. Another factor which must be considered is the time interval between the last amniocentesis and delivery. If very severe disease was forecast then premature induction was performed and the interval was short; whereas if the forecast was of "mild" disease the patient was left to spontaneous delivery. Thus in the underpredicted group there was a longer interval during which maternal antibody levels could have risen and given rise to effects in the fetus (Table I). 
Comparison between these two groups, therefore, must be interpreted cautiously and any conclusions must be tentative.

\section{OVERPREDICTIONS}

All 56 cases in this group were electively delivered prematurely. All were liveborn and by definition had cord haemoglobin values greater than $7.5 \mathrm{~g} / 100 \mathrm{ml}$. This does not mean that all were mildly affected, in fact 28 had haemoglobin values between 7.5 and $11 \mathrm{~g} / 100 \mathrm{ml}$, which indicates relatively severe disease, but none were rhesus-negative, and a further five were only mildly affected and required no treatment. Twenty-three had cord haemoglobin values of greater than $11 \mathrm{~g} / 100 \mathrm{ml}$ but required one or more exchange transfusions.

Premature induction itself carries certain risks and in Table IV we show the mode of delivery for these cases. There is a very high incidence of operative deliveries. Caesarean section was required in about one-third of the cases; the indications are summarized in Table V. At least $10(50 \%)$ of the caesarean sections were performed as a direct result of early intervention and would probably have been avoided had pregnancy been allowed to go to spontaneous delivery.

TABLE IV-Method of Delivery in All Cases

\begin{tabular}{|c|c|c|c|c|c|}
\hline \multicolumn{4}{|c|}{ Delivery } & \multirow{2}{*}{$\begin{array}{c}\text { Underprediction } \\
20(87 \%) \\
0(0 \%) \\
1(4 \cdot 3 \%) \\
2(8.7 \%)\end{array}$} & \multirow{2}{*}{$\begin{array}{c}\text { Overprediction } \\
24(42 \cdot 9 \%) \\
1(1 \cdot 8 \%) \\
11(19 \cdot 6 \%) \\
20(35 \cdot 7 \%) \\
\end{array}$} \\
\hline $\begin{array}{l}\text { Normal } \\
\text { Breech } \\
\text { Forceps } \\
\text { Caesarean }\end{array}$ & $\begin{array}{l}\ldots \\
\cdots \\
\cdots\end{array}$ & $\begin{array}{l}. \\
\cdots \\
\cdots\end{array}$ & $\begin{array}{l}\cdots \\
\cdots \\
\cdots\end{array}$ & & \\
\hline Total & $\ldots$ & $\ldots$ & $\ldots$ & $23(100 \%)$ & $56(100 \%)$ \\
\hline
\end{tabular}

TABLE V-Indications for Caesarean Section in the Overpredicted Group

Placenta praevia

Accidental haemorrhage

Previous caesarean

Failed induction

Seven $(12.5 \%)$ of the liveborn infants died in the neonatal period and the important clinical data for these are summarized in Table VI. From this information prematurity seemed to be the major cause of death in six of these seven infants, and from the haemoglobin values we would not have expected any of these infants to die from haemolytic disease. The case that developed kernicterus emphasizes the danger of hyperbilirubinaemia in premature infants even in the presence of mild haemolytic disease.

It is quite clear that premature induction carries serious implications for the fetus and mother and cannot be justified in patients in whom spontaneous delivery would result in a viable liveborn infant.

Twenty-five out of 85 relevant liquor samples were contaminated with blood. Apart from the fact that these might have been associated with transplacental haemorrhage, blood-stained liquor samples are not suitable for analysis. The presence of haemoglobin distorts the tracing but this can largely be eliminated by measuring the optical density between 490 and $520 \mathrm{~nm}$
(Knox et al., 1965). Measurement of the peak absorption at $450 \mathrm{~nm}$ requires an artificial baseline, the construction of which becomes very arbitrary in haemoglobin-stained samples (Liley, 1961).

Although red cells can be removed easily by centrifugation and the samples may be free from haemoglobin, plasma cannot be removed and, even in small amounts, may alter the tracing and invalidate results. In Fig. 1 we show the effect of adding small amounts of maternal plasma to a clear sample of liquor

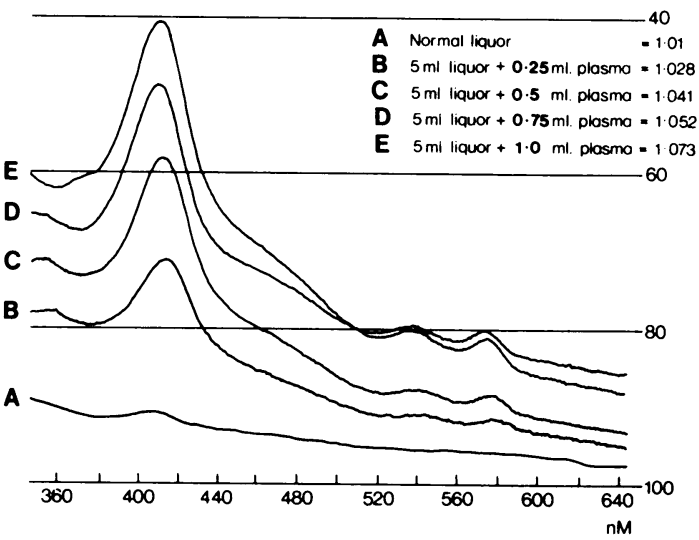

FIG. 1-Liquor contaminated with maternal plasma.

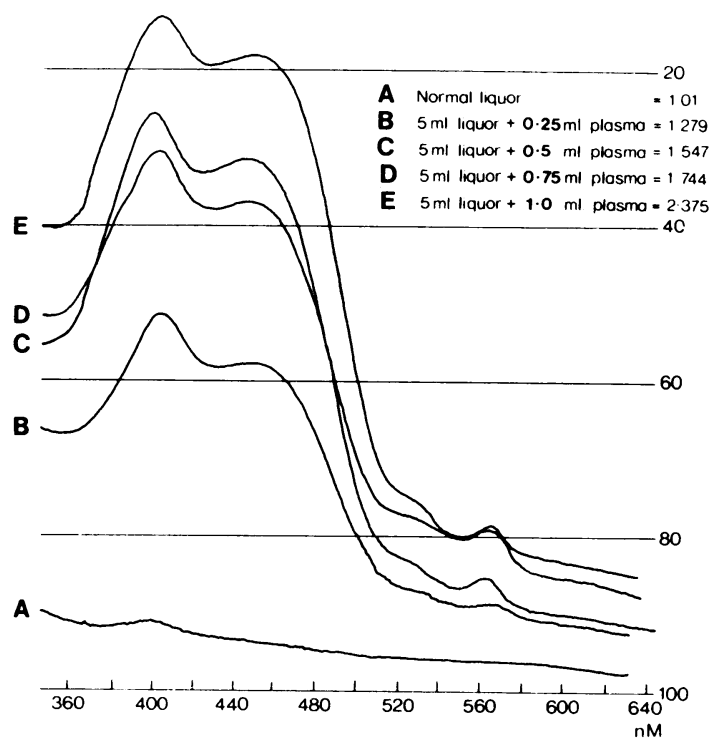

FIG. 2-Liquor contaminated with fetal plasma.

and in Fig. 2 the same experiment using fetal plasma. In both cases serious errors are introduced, but they are much greater with fetal plasma because a severely affected fetus might have a plasma bilirubin value of more than $5 \mathrm{mg} / 100 \mathrm{ml}$ whereas the significant value in "yellow liquor" is often in the $0 \cdot 2-0.5$

TABLE VI-Summary of Neonatal Deaths in Overpredicted Cases

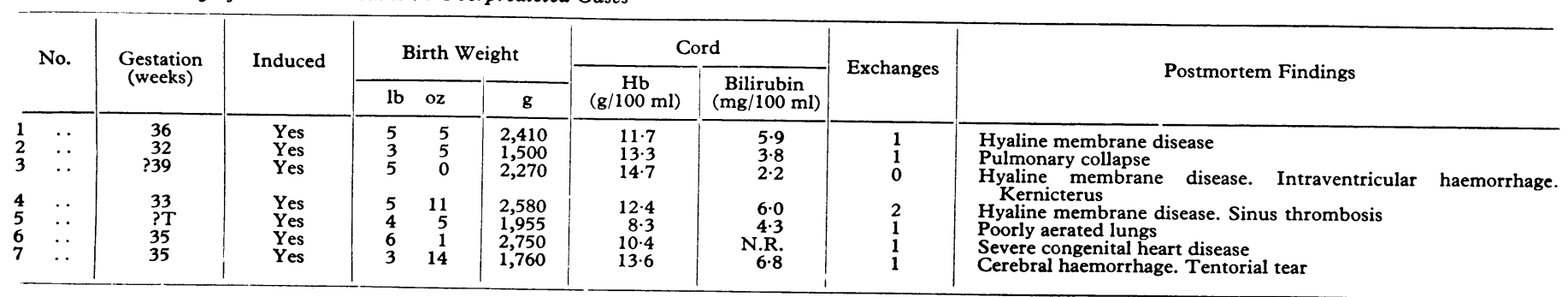


$\mathrm{mg} / 100 \mathrm{ml}$ range. This was undoubtedly the case in a patient in this series who had developed antibodies during the course of the current pregnancy. Liquor obtained at 35 weeks' gestation was heavily. blood-stained and the red cells were shown to be fetal in origin. The liquor bilirubin level was high (ratio 1.156) and because of this labour was induced shortly afterwards. Liquor obtained at the time of induction showed only a low level of bilirubin (ratio 1.04). The infant, although Coombs-positive, was only mildly affected, did not require exchange transfusion, but developed severe respiratory distress syndrome.

Correct assessment of gestation is vital to the interpretation of the liquor bilirubin level as this tends to fall with advancing maturity. It is also relevant to the application of premature induction because the danger to the infant is closely related to the stage of gestation.

In Table VII the birth weights of these infants are plotted against birth weight centiles for recorded gestation. Forty-six

TABLE VII-Comparison of Birth Weights of Liveborn Infants with Expected Birth Weights for Gestation (Thomson et al., 1968)

\begin{tabular}{|c|c|c|c|c|c|}
\hline \multicolumn{4}{|c|}{ Centiles } & \multirow{2}{*}{$\begin{array}{c}\text { Underpredictions } \\
4(28 \cdot 6 \%) \\
3(21 \cdot 4 \%) \\
4(28 \cdot 6 \%) \\
3(21 \cdot 4 \%)\end{array}$} & \multirow{2}{*}{$\begin{array}{c}\text { Overpredictions } \\
27(48 \cdot 2 \%) \\
19(33.9 \%) \\
6(10.7 \%) \\
4(7.1 \%)\end{array}$} \\
\hline $\begin{array}{l}\text { Below 25th } \\
25 \text { th-50th } \\
51 \text { st-75th } \\
\text { Above } 75 \text { th }\end{array}$ & $\begin{array}{l}. \\
\cdots \\
\cdots\end{array}$ & $\begin{array}{l}\ldots \\
\cdots \\
\cdots\end{array}$ & $\begin{array}{l}\ldots \\
\cdots \\
\cdots\end{array}$ & & \\
\hline Total & .. & . & . & $14(100 \%)$ & $56(100 \%)$ \\
\hline
\end{tabular}

$(82 \%)$ fell below the 50 th centile and this difference is statistically highly significant $(P<0.001)$. This could be accounted for either on wrong assessment of gestation or because of retarded intrauterine growth. We have therefore taken into account the clinical evaluation of the infant at birth and the certainty of the calculated expected date of delivery. This we have considered to be in doubt if: (1) the patient stated that she was uncertain of the date of her last menstrual period, (2) her normal menstrual cycle was six weeks or longer, or (3) the last period followed withdrawal of an oral contraceptive agent.

We considered that in 18 of the 56 patients there was good evidence that gestation was less than thought, and indeed 15 of these $18(83 \%)$ had birth weights that fell below the 25 th centile. Uncertainty about the stage of gestation was therefore an important factor in overestimation of the severity of haemolytic disease in the fetus.

\section{Discussion}

Even with the strict criteria used for defining wrong prediction, $88.8 \%$ (636 out of 716 women) were correctly predicted. Thus liquor bilirubin is probably the most accurate single method of predicting the severity of rhesus haemolytic disease (Savage et al., 1966).

Amniocentesis to obtain liquor is being performed with greater frequency in the management of a variety of conditions, as well as haemolytic disease. The technique is not without hazard, the commonest being trauma to the placenta. The incidence of this can be decreased, but not completely eliminated, by previously locating the placenta (Robertson et al., 1969).

Death of the fetus due to blood loss from amniocentesis is uncommon but occurred in three cases where haemolytic disease would probably not have killed the fetus. In the single instance where the cord blood was analysed the haemoglobin was $3 \mathrm{~g} / 100 \mathrm{ml}$, with a bilirubin of $0.8 \mathrm{mg} / 100 \mathrm{ml}$. These findings are more suggestive of severe fetal haemorrhage than severe haemolysis.

Smaller haemorrhages may further sensitize the mother and increase the severity of the disease (Zipursky et al., 1963; Queenan and Adams, 1964). Although it is difficult to prove, the findings in this series strongly suggest that such changes do occur. However, not all women who had rises in the antibody titres or unexpectedly severely affected infants had had traumatic amniocenteses. Kelsall and Vos (1959) found that certain women had a sudden late rise in antibody titre, occurring without previous amniocentesis, which was associated with the development of severe haemolytic disease. They suggested that episodes of immunization, presumably spontaneous fetomaternal haemorrhages, were responsible.

Amniocentesis performed before the 35th week of pregnancy will not detect any later variation in severity. To detect these a further amniocentesis would be required in the last four weeks of pregnancy. But this would increase the hazard of transplacental haemorrhage, especially since there is a reduction in liquor volume near term. In those patients who have had an amniocentesis, but who are allowed to go to spontaneous delivery, a further antibody titre in late pregnancy (37-38 weeks) may enable a late increase to be detected without increasing the risk of placental trauma.

Although transplacental haemorrhage may increase the severity of disease in the infant contamination of the liquor sample by blood may cause an erroneously high bilirubin level. Although it has been known for some time that haemoglobin may affect analysis of liquor (Knox et al., 1965) the effect of plasma contamination seems to be more serious. Thus it appears that analysis of blood-stained samples is not only inaccurate but may be positively dangerous. Samples contaminated with blood should be discarded and not sent for analysis.

Errors in gestational age have also been shown to have an appreciable effect on the interpretation of liquor bilirubin levels. Liley (1961) showed that the level of bilirubin falls from 27 weeks to term in the normal pregnancy, whereas Walker (1970) showed that values diagnostic of severe disease at 32 weeks can be found in normal pregnancies at 28 weeks. In this series overprediction was commonly associated with errors in the assessment of gestation. This may be corrected by routine analysis of liquor for factors which vary with gestation (Lind and Billewicz, 1971) and using these for gestation assessment.

\section{Conclusions}

Although completely accurate prediction has not yet been achieved several recommendations to improve accuracy are made as a result of this study. Placental location should be ascertained before amniocentesis, and the best results are achieved by limiting the technique to a few skilled individuals. Careful attention to clinical assessment of gestational age and assessment of cytological and biochemical criteria in liquor associated with prediction of gestational age will enable more accurate use to be made of liquor bilirubin levels. Blood-stained samples are not suitable for analysis and should be discarded. Because a late rise in antibody titre may follow amniocentesis, blood analysis should be repeated in late pregnancy where the fetus has been predicted to be at low risk.

\section{References}

Kelsall, G. A., and Vos, G. H. (1959). Medical fournal of Australia, 1, 488. Knox, E. G., Fairweather, D. V. I., and Walker, W. (1965). Clinical Science, 28,147 .

Liley, A. W. (1961). American fournal of Obstetrics and Gynecology, 82, 1359.

Lind, T., and Billewicz, W. Z. (1971). British fournal of Hospital Medicine, 5,681 .

Queenan, J. T., and Adams, D. W. (1964). Obstetrics and Gynecology, 24, 530.

Robertson, E. G., Millar, D. G., and Day, M. J. (1968). Fournal of Obstetrics and Gynaecology of the British Commonwealth, 75, 637.

Savage, R. D., Walker, W., Fairweather, D. V. I., and Knox, E. G. (1966). Lancet, 2, 1190.

Thomson, A. M., Billewicz, W. Z., and Hytten, F. E. (1968). Fournal of Obstetrics and Gynaecology of the British Commonwealth, 75, 903.

Walker, W. (1968). Fournal of Obstetrics and Gynaecology of the British Commonweal,h, 75, 1207 .

Walker, W. (1970). British Medical fournal, 2, 220.

Zipursky, A., Pollock, J., Chown, B., and Israels, C. G. (1963). Lancet, 2, 1190. 